\title{
Promoting Peer Review Practice: a Case of Mixed- Proficiency Dyad in Expository Essay Writing Class
}

\author{
Eva Rahmawati \\ Universitas Negeri Surabaya \\ Surabaya, Indonesia \\ evarahmawati@unesa.ac.id
}

\author{
Retno Wulan Dari \\ Universitas Negeri Surabaya \\ Surabaya, Indonesia \\ retnowulan@unesa.ac.id
}

\begin{abstract}
Inability to produce coherent and content-rich expository essays is a major setback for English department students' academic performance. Apart from poor accuracy, poor quality of content and organization of ideas were the major problems. The root of these problems was apparently the lack of feedback, particularly from peers with different levels of proficiency. To cope with the problem, peer review practice was integrated into expository essay writing course to allow transfer of knowledge and strategies among students. To further investigate how the practice was carried out by mixed-proficiency dyads, the current case study focuses on observing the improvements occur in four sophomore students' expository essays during the first half of the semester. The participants were selected as they were the only dyads with a significant difference in writing proficiency levels. In addition to describing the improvements, the study also look at the nature of feedback given by those students. It was eventually revealed that improvement occurs in organization and content aspects, is surprisingly less significant compared to the improvement in vocabulary and language use. Responding to the findings, further research on this subject are still required to throw lights onto the efficacy of peer review for students with different characteristics.
\end{abstract}

Keywords- expository essay writing, mixed-proficiency peer review, transfer of knowledge and strategies

\section{INTRODUCTION}

Despite their frequent use within the context of English for Academic Purpose (EAP), the production of expository essays is also one that poses considerable difficulties. To begin with, the quality of arguments presented in the essay has to be good enough to convince readers. Thus, writers' ability to present opinions formally through adept employment of interactional resources with readers is required [1]. Establishing such interaction is possible only if writers have adequate audience awareness (to engage readers) and sociolinguistics competence that comprises not only that awareness, but also proper use of language and display of authorial attitude [1], [2]. Seeing the many aspects involved in writing expository essay, it is no wonder that beginner writers found this type of essay difficult to produce. Prior to the current study, a preliminary investigation was conducted to a group of students from an English department at a university in Surabaya. The result of this investigation confirmed the problem, which then became the basis for the current study. The problem was further identified as the low quality of content (underdeveloped) and organization, which apparently resulting from lack of modelling of text.
This need of proper examples and responses from audience, represented by peers, for $\mathrm{L} 2$ beginner writers is a notion that has been addressed by several previous research. In particular, these research proposed the implementation of peer review as a means to provide writers with more model texts and feedback from audience [3], [4]. To be precise, peer review allows L2 writers to gain knowledge on how readers respond to text through nonthreatening authentic interactions, which areas of improvements in their writing, and how to do those improvements [2].

However, these propositions were not foolproof solutions to improve performance in writing as the efficacy of peer review depends on many aspects; one of them is the issue of whether or not the reviewer can benefit from peer review activity. While it is believed that receivers of feedback in peer review process do benefit from this practice, the same thing cannot be said for the providers. However, this claim is still debatable as there are research which prove the otherwise. Reviewers could actually gain more advantage and further improve their performance in writing skill than the receivers by incorporating the knowledge they learn in the review process [5]. Almost similarly, another research also suggested that engaging oneself into the process of feedback provision which involves content evaluation, formulation of sensible response, determining strengths and areas of improvements-basically every important aspect in L2 academic writing, would help improve reviewer's performance in writing [6], [7]

Another concern lies in the reviewer's proficiency. There has been arguments that the latter determines the quality of commentaries given, including quantity, type, relevance and accuracy [8], [9]. Concern arises when the reviewer is someone with low proficiency in writing skill. There is a risk that this reviewer might not provide enough feedback [8]. Also, if the reviewer does give feedback, then the feedback given will be too general, have little relevance, or only addresses surface problems [9].

Following this argument, some even reasoned that peer review might not be as effective as teacher or expert review. Supporters of this argument linked peer review's low efficacy to its inability to convince receiver of its usefulness (due to its unpredictable quality) when compared to that of expert review [10]. Nonetheless, this does not mean that peer review should never be incorporated into the teaching of English writing. In response to the aforementioned drawback of peer review, several research highlighted teacher's or instructor's mentoring 
for the reviewers to help solve the problems caused by the discrepancy in proficiency level [9], [11]-[13]. The aim of this practice is to equip reviewers of different levels of proficiency with model of provision strategies, and feedback types that would be more accurate and relevant to their receivers' needs.

Apart from teacher's mentoring, another way to solve problems dealing with different proficiency levels in peer review is by incorporating mixed-proficiency writers in peer review activity. This is not an altogether new idea, as some research have discussed it before. The argument being that with members of peer review activity having different proficiency levels, there is a bigger opportunity of transfer of knowledge [14]. To explain this, peer review activity enables learners to learn particular knowledge in writing besides grammatical accuracy, namely content and style, which they do by making the most of the opportunity to improve themselves via exchanging, sharing, accepting, and appreciating different ideas and views of their peer[15]. During the activity, writer and reviewer are put in a situation where they have to negotiate different point of views, including what they perceive as errors or correct forms and what style they thought would be more welcomed by readers. This process naturally allows for learners with lower proficiency to understand and eventually learn the strategies from their peer with higher proficiency level. In addition to transfer of knowledge, it is even argued that peer review is an effective means of improving learners' critical thinking skills and confidence in writing by exposing learners to frequent instances in providing advices and suggestions for revisions[16]

From the previous discussion, it is suggested that having members with different level of proficiency will increase the beneficial effects of peer review. To better investigate this assumption and provide more tangible proofs for its validity. Four sophomore students were selected from an expository and argumentative essay writing class to be the participants of the study. These students were selected because out of the seven peer review dyads formed in the class, they were the only ones formed by students with major gap in English proficiency levels.

The justification for the aforementioned arrangement was that group or collaborative work could actually help support students' growth as writers. For one, research has shown that collaboration, especially in small groups, not only prove to be effective in improving accuracy in writing, but they can also increase the success rate of problem-solving that deals with language aspect [17]. This mainly to do with the increase of opportunity in seeking out for more advices and suggestions, as well as room for negotiations among peers. In the light of these arguments, it has been decided that the current case study attempted to figure out the contribution of implementing mixedproficiency peer review dyad for the quality improvements in students' written expository essay. In addition, this study also investigated the types of feedback provided by the studentreviewers.

\section{METHOD}

The study took place in a public university that specializes in teacher training program in Indonesia. It was conducted as a case study due to the nature of the investigation, which sought to describe how feedback provided by peers with different level of proficiency could actually contribute to the quality improvement of students' writing. To achieve this purpose, four female sophomore students were selected as the participants of the study. These students coming from an expository and argumentative essay writing class, which implemented the peer review process. Apart from these students, there were ten other students partaking in the course. However, only these four students, under the pseudonym High-Student 1 (HS1), HighStudent 2 (HS2), Low-Student 1 (LS1) and Low-Student 2 (LS2) who were involved in mixed-proficiency peer review dyads with a significant proficiency gap between members (High proficiency - low proficiency pairing).

The first type of data collected in the study is in the form of students' writing profiles taken from three writing assignments during the first half of the semester. The data was obtained by collecting students written essay portfolio during these assignments, which then described by using a profiling rubric [18]. The profiling rubric was chosen, despite it being quite old, because of its reliability and its nature that suits expository and argumentative essays best. The result of the profiling is then described to answer the first research question on the contribution that the mixed-proficiency dyads has for the quality improvement of students' writing.

In addition, to the previous data, the second type of data obtained is in the form of students' feedback profile from three different assignments. This data was collected in the same manner as the first data by using the typology of corrective feedback provided by Rod Ellis [19]. Data obtained via this profiling process is used to answer the second research question concerning with the types of feedback that these students provide.

\section{RESULTS AND DISCUSSION}

Following the two main objectives of the study, the presentation of results and discussion in this section begins with the descriptions of quality displayed by students' written essays in three different essay patterns: exemplification, cause and effect, and comparison and contrast. Following this description, the second half of this section is also dedicated to elaborate the types of feedback provided by the students involved in the peer review activity. To follow the descriptions, the results from the essay and feedback profiling are analyzed by comparing them to related literature. Additionally, each presentation of results is immediately continued by its discussion.

\section{A. The Profile of Students' Written Expository Essays}

The profile of students' written expository essay is obtained through three writing assignments, each of which focuses on different essay patterns: exemplification, cause and effects, and comparison and contrast. Following the essay-profiling rubric, the aspects being described of these essays are the content, organization, vocabulary, language use, and mechanics[18]. Out of these aspects, the ones that pose more gravity are content and organization. This is due to their significant contribution towards the overall quality improvement. As for the categorization used to depict the quality of each aspect mentioned above, the essayprofiling rubric divides it as follow: excellent, very good, good, average, fair, poor, and very poor.

To begin with, both high-proficiency students (HS1 \&HS2) were paired with the two low-proficiency students (LS1 \&LS2). 
The first dyad is the one with HS1 and LS1 as members, while the second dyad has HS2 and LS2 in a team. However, to provide a more comprehensible description of the progress experienced by each students involved in the mixed-proficiency peer review, this section presents the description based on the students' proficiency level.

Data collected on high-proficiency students' written essays reveal that both students' written essays overall quality never fell into any category lower than 'good'. In fact, starting from the first draft of the first assignment (exemplification essay), HS1's essays were already classified as 'excellent' with the content and organization aspects as the dominant contributors for the overall quality. Throughout the three assignments, HS1 shows a constant progress for most writing aspects. Most notably for content aspect which stays in 'excellent' category throughout the three assignments both in first and second drafts. Organization aspect sees an almost similar progress from 'excellent' to 'very good'. For most assignments, it is categorized as 'excellent', except for the third assignment (comparison and contrast essay) where it improves from 'very good' to 'excellent'. A closer examination on this peculiar state reveals that there is a decline in cohesion among paragraphs caused by the use of wrong conjunction as a cohesive device. In addition to these aspects of writing, vocabulary, language use, and mechanics, which represent the student's proficiency level, have a relatively stable category range, starting from 'good' to 'excellent'. It is important to note out, however, that this progress occurred regardless of feedback provided by LS1 as the student-reviewer. For the record, the feedback provided for HS1 are mainly focused on vocabulary, structure, and mechanics.

Slightly different from HS1's profile, HS2's overall written essays' quality can be described as fluctuating from 'good' to 'very good'. On all three assignments, most of her second drafts are categorized as 'very good' with first drafts ranging from 'good' to 'very good'. In terms of content, HS2's works do not have as creative topic of discussion and thorough development of ideas as the ones belong to HS1's works. Apart from this lack of creativity in content, the organization aspect also lacks of more fluent transitions of ideas. In details, for content aspect overall, it is quite dynamic, ranging from 'good' to 'very good' with a tendency to lower in quality as the level of difficulty raises from the first to the third assignment. Unlike the content aspect, the organization aspect is stable on 'very good' category in both first and second drafts throughout the three assignments. Vocabulary and language use are also fairly stable for HS2's works. Vocabulary sees a raising trend from the first to the last assignment. Starting at 'good' category in the first draft of exemplification essay to 'very good' category for the second draft of comparison and contrast essay. As oppose to this, the language use aspect experiences the decline in quality from 'very good' for the first assignment to 'good' in the last assignment. On the side note, the feedback provided for HS2's works are mainly focused in nature and does not cover a wide area of writing aspects. Meanwhile, the mechanics aspect is also stable on 'excellent' category.

Generally, highly proficient students do not experience any changes in the first and second drafts of the first assignment. However, on the second and third assignments, there are significant improvements in almost all aspects in the first and second drafts. A closer look at the aspects with improvements in the works written by HS1 and HS2 reveals that HS1's works improve more extensively in assignment 2 and assignment 3, than HS2's works. This is especially so in the third assignment where the improvement only takes place in vocabulary aspect. Whereas HS1's works improved in three different aspects, namely organization, vocabulary and language use.

Unlike the high-proficiency students, the low-proficiency students' written essays display a different progress altogether. The works of LS1, who is the reviewer of HS1, display an overall quality that ranges from 'fair' to the low 'average'. With this student, the second assignment, cause and effect essay, is the only assignment where the essay fall into 'fair' category. In particular, the content and organization aspects of her essays are most of the time categorized as 'average', with the last assignment in 'fair' criteria. Understandably, the last assignment indeed poses a higher level of difficulty.

Regarding these declines in quality, a closer observation on essays' content aspect reveals the tendency to provide supporting ideas, which do not display the author's sufficient knowledge over the topic being discussed. For instance, in the last assignment about comparison and contrast essay, the author attempted to compare public school and homeschooling by merely providing details that the general audience are already aware of. Such practice suggests the lack of exploration in developing ideas. Notice how she mentions only the major supports, but does not provide a tangible minor support in Figure 1 as follow.

Material that used in formal school and homeschooling are similar. Both of them use the material that suitable with the levels of students. The consideration that they use also similar to choose the material that student needs. Selected materials is selected by the basis of many consideration such as the level of students For instance, both of them use the same material in acquaint the kids in the first class with the math. First they give material about addition, subtraction, multiplication, division and so on.

Fig. 1. Underdeveloped ideas in content aspect.

In the example above, the sentence containing the major supporting idea is 'selected materials is selected by the basis of many consideration such as the level of students'. However, there is only a minor support for the second basis of learning material's selection, the students' level, without any mention about 'the other considerations' stated in the sentence.

Another source of weakness contributing to the low quality of LS1's written essays is the organization aspect. This is particularly so in terms of the fluency of expressions used and the cohesion among ideas from one paragraph to another and within the paragraph itself. An example of this problem can be seen in Figure 2, which is an excerpt taken from the second assignment on cause and effect essay. 


First, make difficult for students. Relocation of rectorat building cause makes some problems for
Ketintang student that felt by Lidah wetan student before. The student which stayed in Ketintang will|
difficult to attend formal events such as ceremony, which always held in front of rectorat building in
Lidah Wetan. Especially for all of Bidikmisi student who must attend some ceremony and new students
who will attend the PKKMB opening ceremony. In addition, student which need to train academic files
or administration get some difficulty because the distance to Lidah Wetan from Ketintang take a long
time, moreover, if they get a traffic jump it really takes a very long time.

Fig. 2. Choppy transition from one paragraph to another.

In the excerpt above, LS1 uses a basic transition signal, the ordinal number, followed immediately by a phrase posing as a topic sentence to link ideas from one paragraph to another. This practice results in a choppy transition which makes the essay less reader-friendly. Interestingly, the low quality in content and organization occurs despite the feedback given which also addresses the content and organization of the essays.

Apart from these problems in content and organization, in general the last three aspects of writing, vocabulary, language use, and mechanics, are also affecting the quality of this student's written essays. Overall, both vocabulary and language use are categorized as 'poor' to 'average' for most of the assignments. In terms of vocabulary, the quality is quite fluctuated, starting from 'fair' in the first assignment, then declining to 'poor' on the second one before finally raising again during the third assignment. The declining quality of vocabulary used in the second assignment is mainly due to the requirement of excessive use of registers dealing with administrative works. Meanwhile, the language use is 'poor' for the majority of assignments given, except for the last assignment where the language use is categorized as 'average'. The feedback given for this aspect is indeed not really sufficient, especially during the first and third assignment. Therefore, it is unsurprising to see the slow progress in these aspects. Mechanics, seems to be the only aspect where the quality tends to rise from the first assignment to the last one by ranging from 'fair' to 'average'.

Contrary to LS1, the overall quality of LS2's written essays is relatively stagnant on the 'average' criteria. There is no significant improvements at all, but there are indeed some peculiar progress with the individual aspects. The first aspect with peculiar development is the content. Albeit having a wider range starting from 'poor' to 'average', this aspect decline in the first assignment from 'average' to 'fair' due to student deleting the parts marked by the reviewer (HS2) to revise. It appears that instead of making the required revision to the problematic parts, the student simply chose to delete the parts entirely. This has caused a gap in information and reduced the coherence in the message delivered by the essay. Directly affected by the decline in content is the organization, which equally declined in quality in the first assignment. This curious occurrence is observable in Figure 3 and Figure 4 as follow.
By using Instagram can also give some disadvantages for the user that has Instagram account.The disadvantages from Instagram, if we over to share our daily activities we can find something that we do not want, such as the case of social media fraud.For example, when we look at the case of many hoax information aboutadmin Instagram account spreading fake chat as Kalporli-Kabid Humas Polda Metro JayalSo we better choose the right information to share with other people and be careful to do something in social media.Because Instagram as

Fig. 3. Content before the omission of poblematic part.

The excerpt above shows the highlighted part that required revisions by rephrasing the sentence and adding more examples to better support the main idea in the topic sentence. In the actual essay, the reviewer has recommended the necessary steps to revise the part. However, the author chose to delete the part instead of rephrasing and elaborating the ideas presented in it. The following excerpt is taken from LS2's essay after the revision stage.

Here are some advantages of using Instagram. First, you can share the
information by communicating to other people. For example, you can give some
comments at the picture of someone's, you can send a direct message to your
friends and also you can find some new followers. Second, you can express
yourself, so you can post some pictures when you want to share to other people.
You can also choose a feature Instastory, so you can share your activities to many
people. The other advantage of sharing information from Instagram, you can
promote something online. For example by making or finding an online shop
account, so you can promote and find some new products that you want to buy or
sell to other people.

Fig. 4. Content after the ommision of the problematic part.

In this revised version, it is apparent that there is no more tangible example present in the essay. The decision to omit the actual case as an example to support the claim presented in the paragraph is a major drawback for the development of content and organization in this exemplification essay. Instead of having a higher quality content and organization, the category of those aspects drops from 'average' to 'fair'.

As oppose to content and organization, vocabulary and language use are two aspects of writing with the tendency to improve in quality both from the first to second draft and from the first to last assignment. Although the range is not too high, from 'poor' to 'average', these two aspects improved considerably after the peer review and revision process. This might indicate a positive response towards the feedback given. Even so, in order to obtain a thorough understanding on how the quality of students' writings is affected by the mixed-proficiency peer review activity, the discussion should take the types of feedback provided into consideration.

\section{B. The Profile of Peer Corrective Feedback}

In the peer review process, the feedback provided are all corrective in nature. All four participants of this study were involved in the process as both reviewers and receivers of feedback. Prior to the practice, there was a brief session of 
training for all of them, in which they were trained to notice errors and lacking in the five aspects of writing: content, organization, vocabulary, language use and mechanics. Therefore, it is assumed that the students are already aware of the parts that require minute review. Nonetheless, there are differences in the types of corrective feedback given. To see the types of feedback provided by the students during the three assignments, please refer to Table 1.

TABLE I. StUdents' CorReCtive FeEdBACK Profile

\begin{tabular}{|l|l|}
\hline \multicolumn{1}{|c|}{ No. } & \multicolumn{1}{|c|}{ Types of Corrective Feedback } \\
\hline 1. & Direct Corrective Feedback \\
\hline 2. & Indirect Corrective Feedback \\
\hline 3. & Metalinguistic Corrective Feedback \\
\hline 4. & Focused Corrective Feedback \\
\hline 5. & Unfocussed Corrective Feedback \\
\hline
\end{tabular}

As seen from the strategy of feedback provision, the most dominant feedback provided by the students is the 'indirect feedback'. In such feedback, the reviewer does not provide the correct form. With the exception of LS1, all the participants of the study provide this type of feedback in various degree of dominance. In particular, HS2 and LS2 who provide this type of feedback dominantly. Feedback on content and organization aspects are mainly in this form, as can be seen in Figure 5.

\begin{tabular}{|l|}
\hline I think, you make the reader confused. Make it clear. \\
Pay attention to dependent and independent sentences. \\
Adding more examples is better.
\end{tabular}

Fig. 5. Indirect corrective feedback.

Direct corrective feedback is also used during the peer review process, especially dealing with errors in vocabulary, language use, and mechanics. The use of this type of feedback is exceptionally dominant in high-proficiency students. It is possible that the domination is supported by the fact that they were able to provide the correct forms of the errors. Whereas with the low-proficiency students, they chose to use this type of corrective feedback when the errors concerned are relatively simple in nature.

The third type of feedback preferred by the students is the metalinguistic corrective feedback. Metalinguistic corrective feedback is quite prevalent in addressing errors that lies in content and organization aspect. This type of corrective feedback is also quite popular with high-proficiency and lowproficiency students alike. Albeit with different quality in terms of the comments given as shown by Figure 6 .

Qr you can put the example in the conclusion
instead.

Fig. 6. Metalinguistic corrective feedback.

Finally, the last two corrective feedback types are the focused and unfocused corrective feedback. These last two types are classified based on whether or not the feedback covers all types of error in the essay. Throughout the three assignments, the feedback provided by the high-proficiency students (HS1 and HS2) are predominantly unfocussed in nature. Understandably, this tendency is driven by the students' better mastery over idea development and organization, vocabulary, language use, and mechanics. As oppose to this tendency, the low-proficiency students (LS1 and LS2) prefer the focused corrective feedback than the unfocused type.

The results of profiling conducted to students' written essays and their feedback during the three assignments proves that there are many factors contribute to the success of peer review activity. During the implementation of the technique, it is important to note that it was quite unlikely for the feedback provision to occur successfully on the first practice. Students need some time to get used to the technique and their peer's characteristics. However, this is just the initial response, on the second and third assignment students were more ready to provide the feedback. Therefore, it might be better for instructor to provide active assistance and supervision during the first practice of peer review activity. Providing a peer review guidelines would be a good step to help students organize their focus during the review process.

In addition to the finding above, there is also a tendency for the low-proficiency students to not make the required revisions after receiving feedback from their peers. There are two possible reasons for this attitude, the reluctance of making revisions and the inability to comprehend the feedback provided by their peers. Therefore, it is important for instructor to not only provide a training on how to provide feedback, but also on how to respond to said feedback.

Eventually, while there is no evidence that the mixedproficiency peer review activity could immediately improve the quality of students' written expository essays. There are evidences proving that it could serve its purpose in a long run. This conclusion is made based on the gradual improvements occur in students' drafts from the first to the last assignment in this study. Although, it should be noted also that the improvements are not significant in nature. Given that they mostly happen to form (vocabulary, language use, and mechanics) instead of content (content and organization).

\section{CONCLUSION}

The results and discussion presented in the previous segment proves that the implementation of mixed-proficiency peer review dyads could help improve the quality of students' writing. This in particular is significant in vocabulary, language use, and mechanics than in content and organization under a short amount of time. To see whether it could significantly improve the content and organization aspects in the longer run, there need to be another research to follow the current one. As for feedback provided by the student, metalinguistic corrective feedback on content and direct corrective feedback on form appear to be the most dominant type throughout the three assignments. Despite these findings, however, the current research is unable to explain why there are instances where the students did not revise their essays following the feedback given. Therefore, more research need to be done to cover this area. 


\section{REFERENCES}

[1] S. H. (Susan) Lee, "Command strategies for balancing respect and authority in undergraduate expository essays," J. English Acad. Purp., vol. 9, no. 1, pp. 61-75, 2010 .

[2] K. Hyland, Second Language Writing. Cambridge: Cambridge University Press, 2003.

[3] H. T. M. Nguyen, "Peer Mentoring: A Way Forward for Supporting Preservice Efl Teachers Psychosocially During the Practicum," Aust. J. Teach. Educ., vol. 38, no. 7, pp. 31-44, 2013.

[4] A. Landry, S. Jacobs, and G. Newton, "Effective Use of Peer Assessment in a Graduate Level Writing Assignment: A Case Study," Int. J. High. Educ., vol. 4, no. 1, pp. 38-51, 2014.

[5] K. Lundstrom and W. Baker, "To give is better than to receive: The benefits of peer review to the reviewer's own writing," J. Second Lang. Writ., vol. 18 , no. 1, pp. 30-43, 2009.

[6] J. R. Chittum and L. H. Bryant, "Reviewing to Learn: Graduate Student Participation in the Professional Peer-Review Process to Improve Academic Writing Skills.," Int. J. Teach. Learn. High. Educ., vol. 26, no. 3, pp. 473-484, 2014.

[7] E. van Popta, M. Kral, G. Camp, R. L. Martens, and P. R.-J. Simons, "Exploring the value of peer feedback in online learning for the provider,"Educ. Res. Rev., vol. 20, pp. 24-34, 2017.

[8] D. Allen and A. Katayama, "Relative second language proficiency and the giving and receiving of written peer feedback," System, vol. 56, pp. 96-106, 2016

[9] I. Chong, "How students' ability levels influence the relevance and accuracy of their feedback to peers: A case study," Assess. Writ., 2016.

[10] T. Hovardas, O. E. Tsivitanidou, and Z. C. Zacharia, "Peer versus expert feedback: An investigation of the quality of peer feedback among secondary school students," Comput. Educ., vol. 71, pp. 133-152, 2014.

[11] H. T. Min, "Effect of teacher modeling and feedback on EFL students' peer review skills in peer review training," J. Second Lang. Writ., vol. 31 , pp. 43-57, 2016

[12] H.-T. Min, "The effects of trained peer review on EFL students' revision types and writing quality," J. Second Lang. Writ., vol. 15, no. 2, pp. 118 $141,2006$.

[13] S. Yu and I. Lee, "Exploring Chinese students' strategy use in a cooperative peer feedback writing group," System, vol. 58, pp. 1-11, 2016.

[14] P. Dao and K. McDonough, "The effect of task role on Vietnamese EFL learners' collaboration in mixed proficiency dyads," System, vol. 65, pp. 15-24, 2017.

[15] F. Mutwarasibo, "Promoting University Students' Engagement in Learning Through Instructor-Initiated EFL Writing Groups," TESOL J., vol. 5, no. 4, pp. 721-742, 2014.

[16] R. Ruegg, "The relative effects of peer and teacher feedback on improvement in EFL students' writing ability," Linguist. Educ., vol. 29, pp. 73-82, 2015.

[17] A. Fernández Dobao, "Collaborative writing tasks in the L2 classroom: Comparing group, pair, and individual work," J. Second Lang. Writ., vol. 21, no. 1, pp. 40-58, 2012.

[18] H. Jacobs, S. Zinkgraf, D. Wormuth, V. Hartfield, and J. Hughey, "No Title," in Testing ESL composition: A practical approach, Rowley: Newbury House, 1981.

[19] R. Ellis, "A typology of written corrective feedback types," ELT J., vol 63, no. 2, pp. 97-107, 2009. 